\title{
REVISÃo DO PLANO DE GERENCIAMENTO DE RESÍDUOS SÓLIDOS NUMA INDÚSTRIA DE CONFECÇÃO
}

\author{
F. K. PEREIRA ${ }^{1}$, M. H. N. OLSEN-SCALIANTE ${ }^{1}$ \\ ${ }^{1}$ Universidade Estadual de Maringá, Departamento de Engenharia Química \\ E-mail para contato: mara@ deq.uem.br
}

\begin{abstract}
RESUMO - Do ponto de vista ambiental e dos processos produtivos utilizados pelas indústrias do setor de confecções faz-se necessário uma investigação a respeito das práticas de gestão dos resíduos gerados em seus processos diante da aplicação da Política Nacional de Resíduos Sólidos. Por isso, o presente trabalho propõe como forma de melhoria contínua da qualidade ambiental de uma empresa a necessidade não só da elaboração de um plano gestor de resíduos sólidos, mas sim uma avaliação contínua do mesmo a fim de propor novas ferramentas e ações de gestão e criação de novas tecnologias. Desta forma o presente trabalho se concentrou na realização de um diagnóstico detalhado da situação de uma empresa do setor de confecção dois anos após a elaboração do Plano de Gerenciamento Integrado de Resíduos Sólidos. Com base no PGIRS já implantado foi possível observar e analisar pontos que servem de bloqueio para o real funcionamento do PGIRS e assim apontar falhas na execução do plano, propor melhorias, apresentar pontos de risco e propostas ações futuras. Dentre as observações realizadas destaca-se a necessidade de criação de uma cartilha para implantação de um programa de capacitação dos profissionais das empresas de confecção para maior mobilização e compreensão de um sistema de gestão de resíduos nas empresas para que seja possível a utilização de ferramentas de qualidade ambiental, tais como SGA+PL.
\end{abstract}

\section{INTRODUÇÃO}

As indústrias de confecção ou de vestuário são responsáveis por transformar os tecidos ou malhas em produtos acabados para fins domésticos e industriais. Tais indústrias movimentam o setor têxtil nacional, sendo apontadas como o segundo maior gerador de primeiro emprego e segundo maior empregador da indústria de transformação (BRASIL, 2012).

Por muitos anos a indústria têxtil esteve despercebida com relação à quantidade de resíduos sólidos gerados. Para Lúcido (2003) a confecção dentro do setor têxtil é uma área praticamente livre de cargas poluidoras, mas do ponto de vista ambiental, talvez seja uma das áreas mais importantes, com aspectos ambientais destacáveis, como por exemplo, a enorme quantidade de aparas de tecidos gerados na fabricação do vestuário. Senger et al. (2009) mostraram que no período de um ano 1.029 toneladas de resíduos foram produzidos em aproximadamente 150 empresas do polo produtor de bonés, em Apucarana, PR. De acordo com informações do Sindicato das Indústrias de Fiação e Tecelagem de São Paulo - Sinditêxtil - SP (2012), só o polo de confecções do Bairro Bom Retiro em 


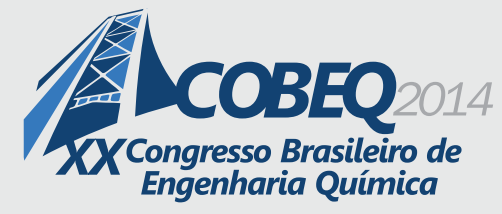

19 a 22 de outubro de 2014

Florianópolis/SC

São Paulo contribui com $2 \%$ do que é produzido no Brasil, cuja estimativa é da ordem de 175 mil toneladas/ano dos quais se estima que apenas cerca de $20 \%$ seja reaproveitado.

Salienta-se ainda que no setor têxtil as cargas poluidoras sejam computadas não somente pela presença da enorme quantidade de retalhos e restos de tecidos (aparas), mas ainda a poluição sonora causada pelo barulho das máquinas de costura, a presença de diferentes embalagens utilizadas: plásticos, papelões, etc. E ainda, resíduo oriundo das manutenções dos equipamentos (Lúcido, 2003).

Para Uliano \& Mattege (2013) há muito tempo a indústria têxtil e de vestuário pertence a um dos setores mais importantes da economia e, cada vez mais, a preocupação com os problemas ambientais causados por esta tem levado vários órgãos e segmentos a questionar e procurar soluções para amenizá-los. Em âmbito nacional, vários órgãos legais foram criados com a finalidade de regulamentar o tratamento ou disposição de resíduos de forma adequada, de modo a minimizar o impacto ao meio ambiente. Por exemplo, a Lei $\mathrm{n}^{\circ} .12 .305$ de Agosto de 2010 (BRASIL, 2010), que instituiu a Política Nacional de Resíduos Sólidos (PNRS), bem como outros mecanismos.

Considerando a ótica ambiental e os processos produtivos utilizados pelas indústrias do setor de confecções, potenciais geradores de resíduos, parece oportuna uma investigação sobre as práticas de gestão dos resíduos gerados em seus processos diante da implementação da PNRS no sentido de identificar os possíveis impactos e implicações da PNRS nessas práticas (FREIRE \& LOPES, 2013) o que pode favorecer a criação de novas ferramentas de gestão, treinamentos e ações e ainda a geração de novas tecnologias.

Desta forma visando à melhoria continua da qualidade ambiental de uma empresa o presente estudo tem como objetivo apresentar um diagnóstico detalhado da situação da empresa dois anos após a elaboração do PGIRS a fim de mostrar o dinamismo proposto pela PNRS e a necessidade de um trabalho continuado.

\section{PROCESSO PRODUTIVO DA EMPRESA ESTUDO DE CASO}

A empresa em estudo é uma indústria do setor têxtil que confecciona peças de vestuário feminino. Sua média produtiva é de 1300 peças/dia. Utiliza tecido natural e sintético como matérias-

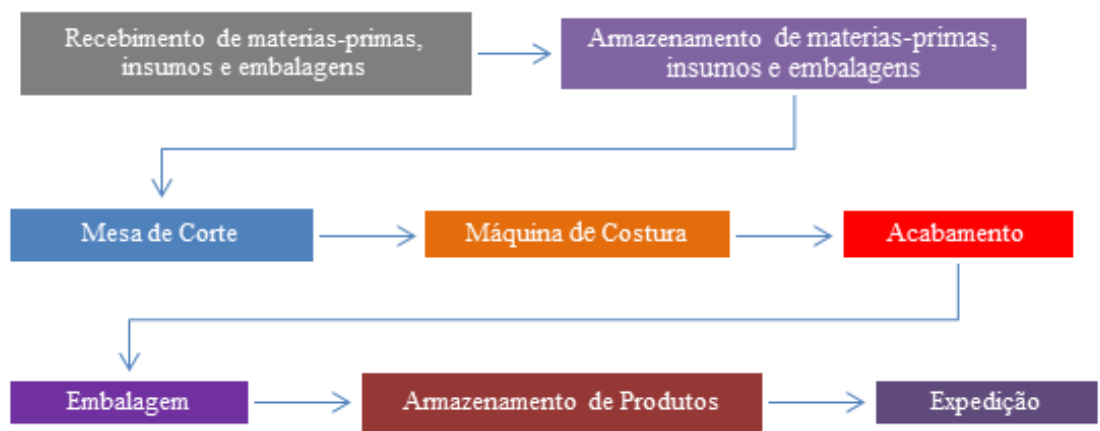

Figura 1 - Etapas do processo produtivo da Empresa Estudo de Caso. 


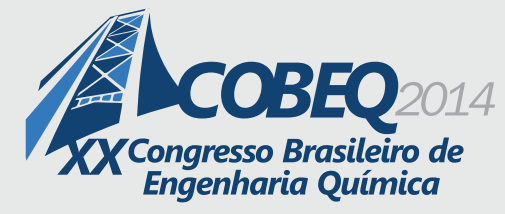

19 a 22 de outubro de 2014

Florianópolis/SC

-primas e tem como principais resíduos gerados os retalhos de tecidos, linhas, papel, papelão e plástico. O processo produtivo da empresa compõe-se basicamente dos setores de estoque, corte, confecção e armazenamento, conforme esquematizado na Figura 1.

\section{DESCRIÇÃO DO PGIRS IMPLANTADO PELA EMPRESA}

O PGIRS apresentado pela empresa foi implantado no ano de 2010 seguindo três fases típicas: (i) levantamento e diagnóstico da situação dos resíduos: etapa na qual foi realizada uma análise das fontes, tipos e quantidades de resíduos produzidos, bem como a gestão empregada; (ii) proposta de gerenciamento de resíduos: a qual esquematizou os passos necessários para gerenciar com eficiência os resíduos sólidos produzidos e (iii) apoio à implantação do PGIRS: nesta etapa foi proposto treinamento e apoio ao grupo de multiplicadores do PGIRS.

O levantamento e diagnóstico realizado durante a implantação do PGIRS permitiu especificar todos os setores da empresa (fontes geradoras) e identificar pontos fortes e oportunidades de melhoria, dentre os pontos fortes apresentados destaca-se que muitos resíduos já eram segregados, as instalações eram limpas e organizadas com equipe comprometida na identificação e resolução de problemas. Como oportunidade de melhoria foi pontuada a identificação de coletores para facilitar a segregação, a readequação do espaço disponível, monitoramento efetivo junto às empresas receptoras e transportadoras de resíduos; monitoramento da quantificação residual e a elaboração de procedimentos específicos para a gestão de resíduos.

Num segundo estágio, observou-se o monitoramento e avaliação da Gestão de Resíduos; composição das ilhas de coleta e considerações sobre o DIR; empresas prestadoras de serviços destinação final dos resíduos; equipe PGIRS; Equipamento de Proteção Individual (EPI's); segurança ocupacional e potencial de redução de resíduos. A observância de cada um desses pontos permitiu a confecção de planilhas eletrônicas para monitoramento e gerenciamento dos resíduos, avaliando qualita-quantitativamente os resíduos sólidos gerados demonstrando as formas de destinação final, bem como os custos e receitas advindas do gerenciamento. Além deste monitoramento, o PGRS previu uma avaliação efetiva do envolvimento das partes na gestão proposta através de vistorias setoriais na empresa e ainda, um controle eficaz das documentações e ações legais exigidas das empresas transportadoras e receptoras a fim de obter maiores subsídios para um controle efetivo da implantação, manutenção e aprimoramento do PGIRS. Todos os instrumentos e instruções voltados para tais fins foram compilados no procedimento Gestão de Resíduos Sólidos.

Com relação à equipe executora, foi proposto integrantes com suas respectivas atribuições para a implantação e monitoramento contínuo do plano de gerenciamento dos resíduos sólidos. Um ponto importante ressaltado no PGRS é que o pessoal envolvido diretamente com o gerenciamento de resíduos deve ser capacitado na ocasião da sua admissão e mantido sob treinamento periódico para desempenhar as atividades de manejo de resíduos, incluindo a responsabilidade com a higiene pessoal e dos materiais utilizados para tal fim, lembrando que todos os funcionários que trabalham na empresa devem conhecer o gerenciamento proposto, independentemente de serem integrantes ou não da equipe de implantação do plano na empresa. 


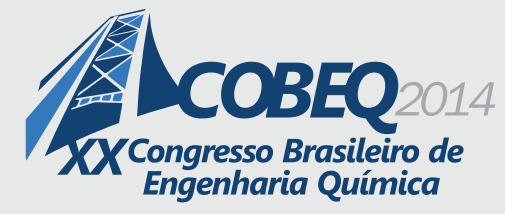

19 a 22 de outubro de 2014

Florianópolis/SC

Ao avaliar o potencial de redução de resíduos, houve destaque para algumas medidas preventivas que poderiam ser adotadas para evitar a geração de resíduos ou para reduzir o volume e a toxidade dos mesmos. Essas medidas foram apontadas como: redução na área administrativa (treinamento dos funcionários, implantação de sistemas de monitoramento da qualidade, orientação de fornecedores, etc), reutilização na área administrativa e reutilização na produção.

Por fim foi possível concluir que o treinamento contínuo e a sensibilização é um dos fatores mais importantes para o sucesso do PGIRS, pois somente através da equipe consciente e comprometida é possível atingir os objetivos pretendidos. O PGIRS indicou uma série de temas relacionados à sensibilização quanto às atitudes ambientalmente corretas, formas de tratamento e disposição final dos resíduos e procedimentos a serem adotados pela empresa. O PGIRS ainda apresentou um cronograma propondo a revisão e atualização anual do PGIRS.

\section{DIAGNÓSTICO ATUAL - REAVALIANDO O PGIRS}

Para uma efetiva avaliação do plano gestor implantado, realizou-se um diagnóstico detalhado com relação ao gerenciamento de resíduos. Inicialmente fez-se uma inspeção de risco mediante entrevistas técnicas e reuniões com supervisor e profissionais do setor produtivo. Tal inspeção permitiu identificar possíveis perdas e que embora haja setores que proporcionem desconforto não há pontos vulneráveis a ocorrência de acidentes ou de emergência ambiental na empresa.

O PGIRS atual destaca que o processo de serigrafia é terceirizado por isso não há utilização de substancias química como tintas ou solventes no processo produtivo. Foram identificados pontos em não conformidade, tais como no armazenamento temporário dos resíduos, pois ocorre a mistura dos resíduos dentro das baias, a sobrecarga e não há meio de impedir o contato de pessoas não autorizadas ou de animais.

Observou-se que a empresa não detém todas as informações necessárias a respeito da empresa responsável pelo destino final dos resíduos o que confere risco considerável com relação a possíveis sanções, afinal a Legislação prevê a responsabilidade do órgão gerador o resíduo desde a sua geração até o destino final (Lei Federal 9.605, de 12 de fevereiro de 1998; Lei Estadual nº 14.248 de 29 de julho de 2002).

\subsection{Identificação dos Resíduos Sólidos Gerados}

A identificação dos resíduos gerados foi qualitativa e quantitativamente. Os resíduos presentes no processo como um todo são: restos de alimentos (oriundos do refeitório), lâmpadas fluorescente, papel, papelão e plástico, resíduos de varrição, óleo lubrificante gerado pelas máquinas de costura, restos de tecidos contaminados ou não com óleo. Os resíduos foram identificados por setor e quantificados. A tabela 1 exemplifica os resultados para alguns setores 1.

O PGIRS implantado previu uma avaliação efetiva do envolvimento das partes na gestão proposta através de vistorias setoriais na empresa e ainda, um controle eficaz das documentações e ações legais exigidas das empresas transportadoras e receptoras a fim de obter maiores subsídios para 


\section{LCOBEQ 2014}

um controle efetivo da implantação, manutenção e aprimoramento do PGIRS. Na realização do diagnóstico foi possível observar que tais ações não foram realizadas. As planilhas referentes a essas informações encontram-se totalmente desatualizadas e incompletas.

Tabela 1. Diagnóstico da geração de resíduos por setor ou fonte geradora.

\begin{tabular}{|c|c|c|c|c|c|c|c|c|c|}
\hline \multirow[t]{2}{*}{ Setores } & \multirow[t]{2}{*}{ Resíduo } & \multirow[t]{2}{*}{ Descrição } & \multirow{2}{*}{$\begin{array}{c}\text { Classificação } \\
\text { NBR 10004 - } \\
\text { CONAMA } 313\end{array}$} & \multicolumn{2}{|c|}{$\begin{array}{c}\text { Total gerad0, } \\
\text { kg }\end{array}$} & \multirow[t]{2}{*}{$\begin{array}{c}\text { Acondicionamento na } \\
\text { empresa }\end{array}$} & \multirow[t]{2}{*}{$\begin{array}{l}\text { Empresa de } \\
\text { transporte }\end{array}$} & \multirow[t]{2}{*}{$\begin{array}{l}\text { Empresa } \\
\text { receptora }\end{array}$} & \multirow[t]{2}{*}{$\begin{array}{l}\text { Destino } \\
\text { final }\end{array}$} \\
\hline & & & & Dia & Mês & & & & \\
\hline \multirow{8}{*}{$\begin{array}{l}\text { Distribuição e } \\
\text { corte }\end{array}$} & \multirow[t]{2}{*}{ Papéis } & $\begin{array}{l}\text { Papel kraft, } \\
\text { papel branco, } \\
\text { revistas, } \\
\text { envelopes, } \\
\text { rascunhos }\end{array}$ & IIB & 1,23 & 2589 & Sacos plásticos $(5 \mathrm{~L})$ & $\begin{array}{l}\text { Coleta } \\
\text { pública }\end{array}$ & $\begin{array}{l}\text { Coleta } \\
\text { pública }\end{array}$ & $\begin{array}{c}\text { Aterro } \\
\text { municipal }\end{array}$ \\
\hline & & $\begin{array}{l}\text { Caixas de } \\
\text { embalagens }\end{array}$ & IIB & 0,17 & 3,51 & DIR & $\begin{array}{l}\text { Pessoa } \\
\text { física } \\
\text { (catador) }\end{array}$ & cooperativa & reciclagem \\
\hline & Plástico & Embalagens & IIB & 0,10 & 2,10 & Sacos plásticos $(5 \mathrm{~L})$ & $\begin{array}{l}\text { Coleta } \\
\text { pública }\end{array}$ & $\begin{array}{l}\text { Coleta } \\
\text { pública }\end{array}$ & $\begin{array}{c}\text { Aterro } \\
\text { municipal }\end{array}$ \\
\hline & \multirow[t]{3}{*}{ Têxtil } & Algodão & \multirow[t]{3}{*}{ IIA } & \multirow[t]{3}{*}{3,30} & \multirow[t]{3}{*}{69,30} & \multirow{3}{*}{$\begin{array}{c}\text { Recipiente plástico } \\
\text { (110L) }\end{array}$} & \multirow[t]{3}{*}{$\mathrm{RE}^{*}$} & \multirow[t]{3}{*}{$\mathrm{RE}^{*}$} & \multirow[t]{3}{*}{ reutilização } \\
\hline & & $\begin{array}{c}\text { Poliester, } \\
\text { poliamida, } \\
\text { polipropileno, } \\
\text { látex }\end{array}$ & & & & & & & \\
\hline & & $\begin{array}{c}\text { Mistura de } \\
\text { fibras } \\
\text { naturais e } \\
\text { sintéticas }\end{array}$ & & & & & & & \\
\hline & $\begin{array}{c}\text { Material } \\
\text { contaminado }\end{array}$ & $\begin{array}{l}\text { Espuma } \\
\text { contaminada } \\
\text { com tintas, } \\
\text { vernizes, } \\
\text { solventes, etc }\end{array}$ & I & 0,23 & 4,89 & Sacos plásticos $(5 \mathrm{~L})$ & $\begin{array}{l}\text { Coleta } \\
\text { pública }\end{array}$ & $\begin{array}{l}\text { Coleta } \\
\text { pública }\end{array}$ & $\begin{array}{c}\text { Aterro } \\
\text { municipal }\end{array}$ \\
\hline & Rejeito têxtil & $\begin{array}{l}\text { Material não } \\
\text { reciclado } \\
\text { (poeira e } \\
\text { resíduos de } \\
\text { linha) }\end{array}$ & IIA & 0,03 & 0,69 & Sacos plásticos $(5 \mathrm{~L})$ & $\begin{array}{l}\text { Coleta } \\
\text { pública }\end{array}$ & $\begin{array}{l}\text { Coleta } \\
\text { pública }\end{array}$ & $\begin{array}{c}\text { Aterro } \\
\text { municipal }\end{array}$ \\
\hline
\end{tabular}

* o nome da empresa foi preservado.

O plano gestor recomenda que os resíduos gerados na facção retornem à empresa geradora, permanecendo temporariamente no DIR antes do destino final adequado. Desta forma, propõe-se que toda movimentação de resíduos seja registrada e documentada em planilha de acordo com instrução da NBR 12235/92.

Dentre todas as observações apontadas e realizadas, ficou claro que o PGIRS aplicado na em empresa no ano de 2010, até a presente dada não passou por nenhuma manutenção ou aprimoramento após sua implantação. Essa falta de reavaliação anual ou monitoramento do PGIRS implantado foram os responsáveis pelo surgimento e descumprimento de requisitos necessários para que o PGIRS funcionasse com total eficiência apresentando desta maneira pontos em não conformidade. Dentro da empresa não existe o monitoramento dos resíduos o que auxiliaria no controle e formação de um banco de dados, com relação à quantidade, tipo ou classe e qual é o seu real destino assim como custo envolvido. Ao analisar esses pontos foi possível propor algumas melhorias, tais como uma melhoria na segregação dos resíduos a partir da implantação de ilhas de coleta. Foram iniciados estudos logísticos criando um documento de frequência entre as coletas assim como a quantidade gerada por cada setor, transporte interno dos resíduos já segregados até a área onde estão alocados os DIR's. 


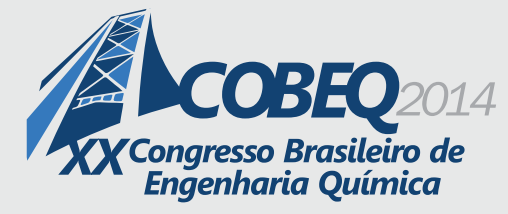

Com relação aos DIR's observou-se o não cumprimento das normas estabelecidas pelo plano gesto, apresentando-os com mistura de resíduos de classes distintas e sobrecarga. Foi sugerido a realização de algumas modificações em suas estrutura física.

Durante o período de observação, realizou-se o acompanhamento do receptor que realizava a coleta de resíduos na empresa a fim de verificar a veracidade das informações prestadas, evitando-se assim que a empresa geradora sofresse penalizações devido as infrações e sanções administrativas ao meio ambiente que constam no Decreto 6.514, de 22 de julho de 2008, devido à má conduta de empresas contratantes.

Outro problema observado relaciona-se com a enorme quantidade de tubos plásticos gerados do consumo de rolos de tecidos. Tal material poderia ser aproveitado eficientemente por cooperativas para confecção de artigos de artesanato e/ou móveis, como pufs. Para tanto, salienta-se a necessidade urgente da implantação de um grupo gestor dentro da empresa, outra dificuldade encontrada, afinal, o plano gestor inicial o propunha e por isso foi batizado como PGIRS, porém, nunca foi realizado, sequer o treinamento de funcionários para tanto.

A confecção de artigos como almofadas, pufs e outros artigos de artesanato pode ser uma alternativa importante para a empresa se destacar no setor ambiental e também social. Uma boa redução de custos com tratamento e destino final pode ser alcançada, aliando a entrega dos resíduos em organizações sociais que possam agregar valor, reaproveitando tais resíduos. A questão pode inicialmente parecer problemática, devido a documentação necessária, porém, a cidade já encontra algumas associações organizadas de tal modo que têm capacidade de receber esses resíduos, fornecendo documentação necessária para a garantia do andamento do PGIRS implantando pela empresa.

A criação de um grupo gestor dentro da empresa se faz necessário devido à falta de orientação, monitoramento, e treinamento periódicos dos colaboradores sobre a importância que cada um tem sobre a cadeia de gestão integrada de resíduos sólidos gerados pelos diversos setores. O ponto chave dos membros do grupo gestor é o de conscientização dos diversos colaboradores e mostrar quais são as suas responsabilidades e cuidados a serem tomados com o que é gerado, mas também como eles devem gerenciar os resíduos sólidos, e os cuidados que eles devem ter com a sua higiene pessoal pelo fato de estarem em contato direto com os resíduos. O grupo gestor vem para auxiliar tanto na implantação e monitoramento do PGIRS, mas principalmente na pós-implantação garantindo desta maneira sua máxima eficiência. Cada membro do grupo deve possuir função e atribuição determinadas garantindo uma constante e abrangente análise de dados e fatores críticos a serem eliminados ou evitados mantendo uma constante manutenção da qualidade do PGIRS dentro da empresa.

O grupo tem a função de garantir a qualidade do PGIRS por meio de ações como: (i) treinamento contínuo dos colaboradores; (ii) realização de análises dentro da que possam identificar pontos não conformes com as especificações exigidas pelas normas em vigor e assim escolher a melhores ferramentas de correção dessas não conformidades. (iii) difundir e consolidar entre os colaboradores da empresa o envolvimento dos diversos setores da empresas sobre uma visão 


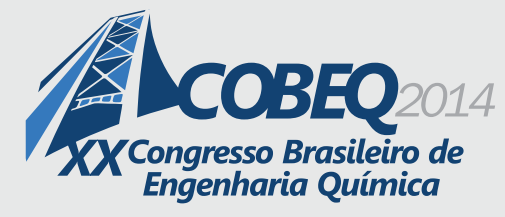

19 a 22 de outubro de 2014

Florianópolis/SC

sustentável por meio de treinamentos, dinâmica de grupo, ações que estimule a mudança de visão de todos envolvidos sobre as consequência de suas ações não apenas no meio de trabalho mas também em sua vida social. (iv) criar e propor grupos sociais; (v) divulgar e expandir trabalho de reaproveitamento de resíduos pela empresa e (vi) propor sempre novas ideias. Todas essas atribuições partem de um efetivo trabalho de educação ambiental dentro da empresa. No decorrer do desenvolvimento de trabalho, apesar de ter sido um dos objetivos, não foi possível iniciar treinamento dos funcionários. Apesar das barreiras apresentadas, essa ideia não foi descartada e tem sido avaliada pela administração da empresa.

\section{CONCLUSÃO}

O Plano implantado em 2010 não havia sofrido nenhuma avaliação até o presente trabalho. O que permitiu apontar críticas e possíveis melhorias na adequação e inserção dos recipientes destinados ao armazenamento temporário assim como sua identificação. A falta de padronização e registro dos procedimentos realizados invalida o plano gestor implantado. Os funcionários desconhecem a existência do PGIRS, o que invalida a implantação de outras ferramentas da qualidade, tal como SGA + PL. A empresa possui potencial para trabalho social podendo trabalhar com o conceito de responsabilidade ambiental.

\section{REFERÊNCIAS}

AGUIAR, Silvio. Integração das ferramentas da qualidade ao PDCA e ao programa seis sigma. Belo horizonte: Editora de Desenvolvimento Gerencial, 2002.

CALDERONI, S. Os Bilhões Perdidos no Lixo. 3a . Edição. Editora Humanitas, São Paulo, 1999.

CASTR0 SILVEIRA, M.M. 2000. Sistema de Gestão Ambiental (SGA) - Tipologia do empreendimento: Indústria Têxtil. Monografia - Especialização em Gestão Ambiental. FEAFUMEC. Belo Horizonte-MG.

DIAS, R.. Gestão Ambiental: Responsabilidade Social e Sustentabilidade. 1. Atlas, São Paulo. 2009

DRUZZIAN, E.T.V., SANTOS, R.C. 2009. Sistema de gerenciamento ambiental (SGA): buscando uma resposta para os resíduos de laboratórios das instituições de ensino médio e profissionalizante. Monografia - Especialização em Educação Ambiental à distância. SENAC (Serviço Nacional de Aprendizagem Comercial). Porto Alegre.

GERBER, Wagner. Impacto ambiental: resíduos sólidos e reciclagem. Pelotas : UCPEL, 1999. p.40.

KASEVA, M. E.; GUPTA ,S. K.; Recycling - an environmentally friendly and incomegenerating activity towards sustainable solid wastemanagement. Case study - Dar es Salaam City, Tanzania. Tanzania, 1996.

LÚCIDO, G. L. A., A edicação ambiental na área têxtil. Revista ABTT, Rio de Janeiro. Ano 2, n.4, p. 18-19, set 2003. Disponível em: 〈http:www.abtt.org.br/revistas.asp>. Acesso em: $02 / 04 / 2014$

MOURA, L. R. Qualidade simplesmente total: uma abordagem simples e prática da gestão da 
qualidade. Rio de janeiro: Qualitymark Ed. 1997.

PINTO-COELHO, E. M. Reciclagem: desenvolvimento sustentável no Brasil. [s.I.]: Recóleo, 2009.

SENGER, Carine Maria et al. Conscientização empresarial quanto à correta destinação de resíduos sólidos da confecção de bonés na cidade de Apucarana. 2009. (Congresso Internacional de Administração - $\quad$ set/2010). Disponível em: http://intertemas.unitoledo.br/revista/index.php/ETIC/article/viewFile/2529/2053. .Acesso em: 29 jul. 2013.

SINDICATO DAS INDÚSTRIAS DE FIAÇÃO E TECELAGEM DO ESTADO DE SÃO PAULO.
$\begin{array}{ll}\text { Retalho } & \text { fashion. }\end{array}$ $\begin{array}{llr}\text { Retalho } & \text { fashion. } & \text { Disponível } \\ \text { http://sinditextilsp.org.br/images/stories/APOIO_4/Apresentao_Retalho_Fashion.pdf }>\text {. Acesso em: } 29\end{array}$ jul. 2013.

TACHIZAWA, Takeshy Gestão ambiental e responsabilidade social corporativa : estratégias de negócios focadas na realidade brasileira / Takeshy Tachizawa .- 4. ed. revista e ampliada - São Paulo : Atlas, 2006.

UliANO, J. DE C.; MATTGE, K.; ALMEIDA, A. A. Reuso de Resíduos Sólidos Têxteis para Oficinas de Confecções. Iniciação Científica CESUMAR- jan./jun, v. 15, n. 1. 2013.

ZUMBACH, L.; MORETTI, G. ISSO 14001 Comentada. Disponível em http://necs.preservaambiental.com/ciclo-pdca-abordagem-de-processo-e-escopo-do-sistema-degestao-ambiental. Data de acesso: 12 de outubro de 2013. 